\title{
The spinal cord in rheumatoid arthritis with clinical myelopathy: a computed myelographic study
}

\author{
JOHN M STEVENS, ${ }^{* \dagger}$ BRIAN E KENDALL ${ }^{*}$ H ALAN CROCKARD* $\ddagger$ \\ From the National Hospitals for Nervous Diseases, ${ }^{*}$ St Mary's Hospital, $\uparrow$ and the Middlesex Hospital, $\ddagger$ \\ London, $U K$
}

SUMMARY Thirty one patients with suspected myelopathy due to rheumatoid arthritis were examined by plain radiography and 27 had computed myelography. Clinical features and radiological findings were compared. Deformity of the spinal cord could occur in the absence of combined anterior and posterior compression and correlated closely with clinical features only when considered in combination with skeletal and adjacent soft tissue abnormalities. The best surgical results were achieved by transoral odontoidectomy.

The myelopathy associated with long-standing rheumatoid arthritis is acknowledged to be due to spinal cord compression in the great majority of cases. The mechanisms by which the cord may be compressed have been described extensively. ${ }^{1-4}$ However, it is recognised that the degree of atlanto-axial subluxation shown on plain radiographs is not related closely to the presence of myelopathy. ${ }^{4-6}$ Even when the minimum sagittal diameter of the spinal canal has been taken into account there remain a considerable number of cases where compression cannot be inferred from plain radiographs alone. ${ }^{78}$ Indeed, Stevens et al found seven of 24 patients with myelopathy in whom the minimum sagittal diameter of the canal exceeded 16 millimetres. ${ }^{8}$ Redlund- Johnell and Petterson have recently shown that vertical atlanto-axial subluxation has the highest incidence of myelopathy, ${ }^{9}$ but this accounts for only a minority of cases. Alternative mechanisms have been suggested, based in the main on observations from isolated case reports: nonbony granulomatous masses, ${ }^{121011}$ vertebral artery compression or thrombosis, ${ }^{1213}$ and ischaemic myelomalacia from small vessel disease. ${ }^{48}$

Adequate clinical investigation can be difficult in these patients. Myelography has been performed infrequently in most published series, the concensus opinion being that it should be reserved only for those cases where subluxation alone was inadequate to explain the myelopathy, and to localise the site of

Address for reprint requests: Dr JM Stevens, The National Hospital for Nervous Diseases, Maida Vale, London W9 ITL, UK.

Received 24 April 1985 and in revised form 9 July 1985. Accepted 13 July 1985 cord compression where this was in doubt. ${ }^{248141516}$ Computed tomography (CT) has been advocated recently because it has detected more erosions, accurately defined the pathological anatomy in severely deformed patients, and shown soft tissue as well as bony abnormalities. ${ }^{17-19}$ However, a bettę definition of soft tissue and neural elements is pro® vided if $C T$ is performed after the introduction o intrathecal water-soluble contrast medium, that is computed myelography and cisternography. ${ }^{2021}$

At the National Hospital for Nervous Diseases (Maida Vale), we have been performing regularly both conventional and computed myelography on such patients and have been impressed by the greater understanding these studies have provided of the mechanical factors affecting both cord structure and function. In addition to localising accurately the site of maximum cord involvement, the importance of anterior deformation of the spinal canal regardless of the width of the subarachnoid space dorsal to the cord has been revealed. This data has enabled us to follow a surgical approach for these patients which has thus far yielded better results than other commonly reported surgical methods.

The purpose of this study has been to examine the correlations between clinical features, abnormalities on plain radiographs, and the pathological anatomy revealed by computed myelography, and to use these to establish a more acceptable concept of cord compression than can be gleaned from existing literature.

\section{Materials and methods}

Our material consisted of 31 patients with rheumatoid 140 


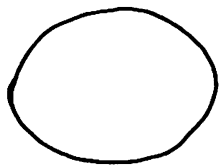

Normal 6 cases

Average sagittal diameter $9.8 \mathrm{~mm}$

Range 8-11mm

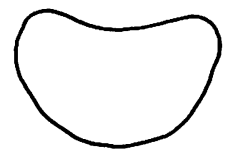

Moderate 9 cases

Average sagittal diameter $6.8 \mathrm{~mm}$

Range 6-8mm

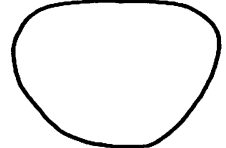

Mild 7 cases

Average sagittal diameter $8.2 \mathrm{~mm}$

Range $8-10 \mathrm{~mm}$

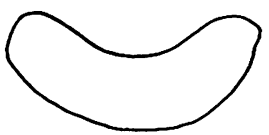

Severe 5 cases

Average sagittal diameter $4.0 \mathrm{~mm}$

Range 2-5mm

Fig 1 Classification of deformities of external form of the spinal cord at the cranio-vertebral junction, also applicable to subaxial levels. Measurements are compared to classification by visual assessment.

arthritis referred to the National Hospitals for Nervous Diseases (Maida Vale) and St Mary's Hospital (Paddington) with suspected compressive cervical myelopathy. There were 19 females and 12 males, and the age range was 22 to 77 years. All were investigated by plain radiographs, 29 had water-soluble myelograms performed by lumbar puncture, of which 27 were followed by CT on a GE 8800 or Somaton II scanner. Slice thicknesses of $1.5 \mathrm{~mm}-2 \mathrm{~mm}$ were performed sequentially across the foramen magnum and $5 \mathrm{~mm}$ thick slices were made with $2 \mathrm{~mm}$ overlap between slices to examine the cervical spine from C.2 to T.1. Sagittal and coronal reformatted images were prepared from this data. All patients were scanned supine with the head supported in a neutral position, and in six, the foramen magnum region was scanned in both flexion and extension. Measurements were taken of the mid-sagittal diameters of cord, bony canal, theca and width of the subarachnoid space anterior and posterior to the cord. In addition to measurements, a visual classification of the variations in cross-sectional shape of the cord was devised: loss of normal anterior convexity was designated mild, anterior concavity moderate and obvious antero-posterior flattening severe deformity (figs 1, 2, 3 and 4).

Measurements were made from plain radiographs according to methods described by Inger Redlund-Johnell, including minimum mid-sagittal diameter of the bony canal. ${ }^{1}$

Clinical features were arranged to conform in general with those discussed by other authors, and they will be defined in the Results section. Each was compared with the radiological variables defined above. Operation was performed on 24 patients. Six had posterior occipito-vertebral or atlantoaxial fusions, eight had subaxial fusions and 15 had transoral odontoidectomy combined with posterior fusion. The technical aspects of the latter are described elsewhere. ${ }^{22}$ Some patients having subaxial fusions had cranio-vertebral operations as well. Follow up periods varied from three months to four years, and not all operations were performed by the same group of surgeons.

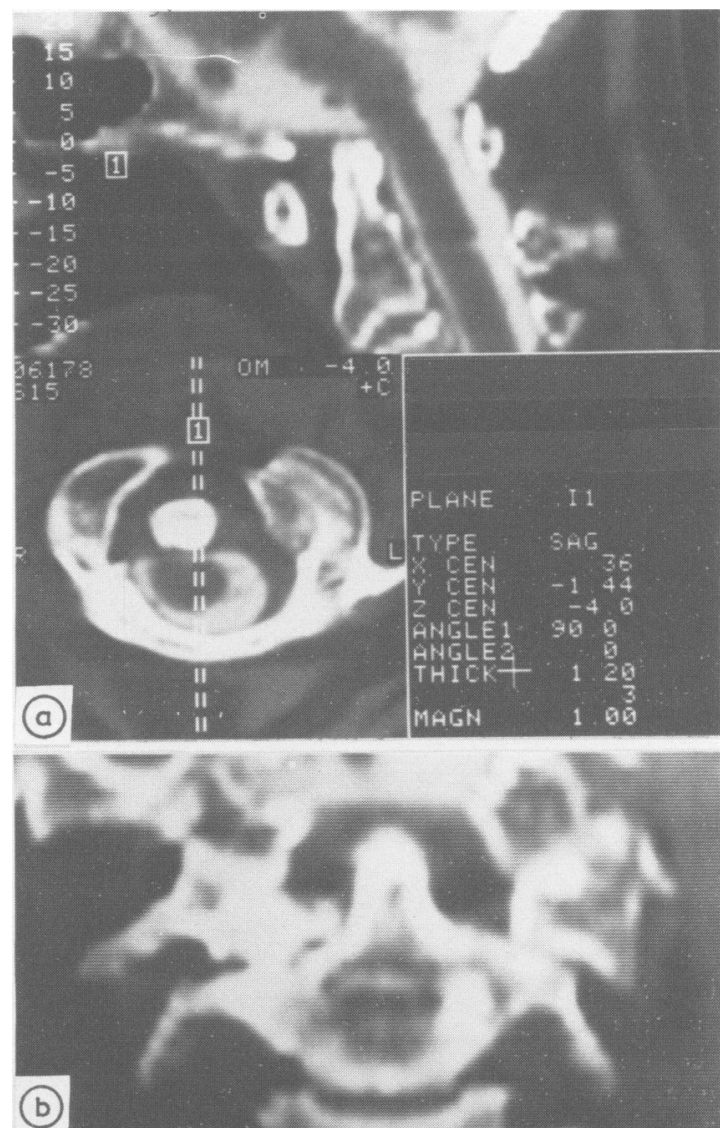

Fig 2(a) Axial CT with sagittal reformat. Note atlanto-axial subluxation, and mild congruous cord deformity on the axial image which is only just perceptible on the sagittal image. (b) Coronal reformat, showing lateral atlanto-axial subluxation which the axial image in (a) shows to be associated with more distortion of the right side of the cord. This patient had left arm paraesthesia.

Statistical significance was calculated using Fisher's Exact Probablility Test.

\section{Results}

The results are presented as follows: (1) observations on the spinal cord from computed myelography, (2) skeletal and soft tissue factors (3) correlations with clinical features, and (4) results of the various types of operative procedure.

\section{The spinal cord}

On CT the cross-sectional shape of the cord was either normal or deformed. Two kinds of deformity occurred: those "mirroring" deformations of the theca, which were called congruous or "com- 


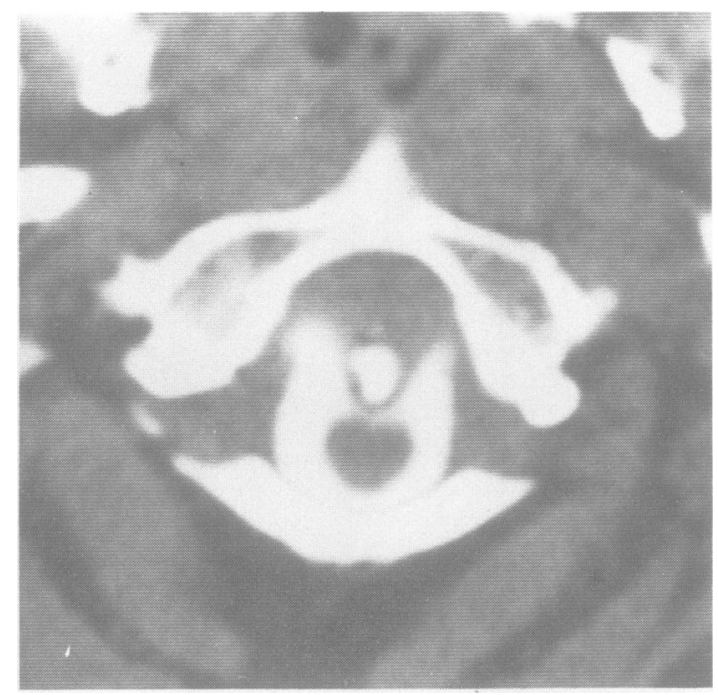

Fig 3 Axial CT. Moderate congruous cord deformity.

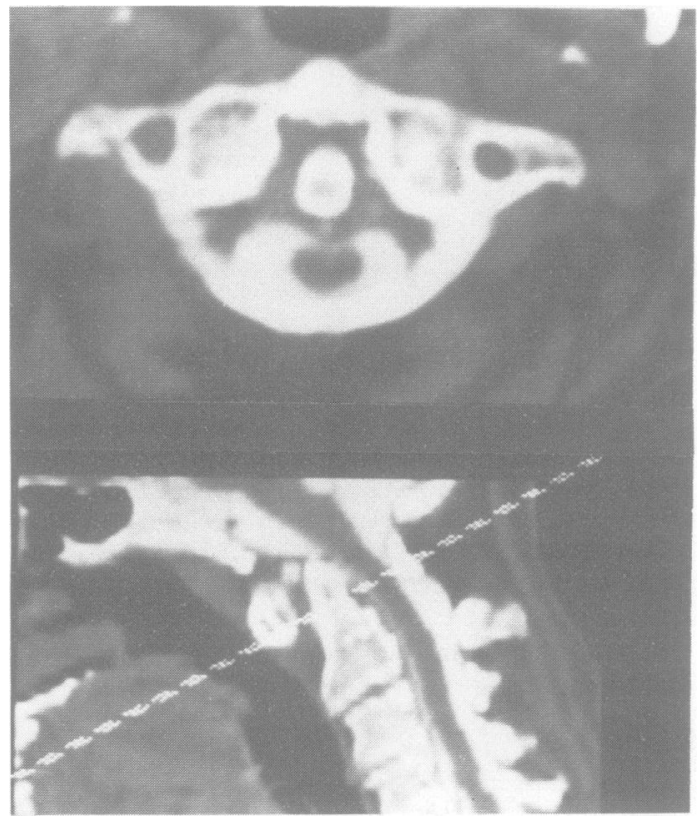

Fig 4 Axial CT with sagittal reformat. Severe congruous cord deformity. Note the small ossific nodule lying in the atlanto-dental interval, and this subluxation was immobile on plain radiographs.

pressive", and those unassociated with thecal deformation at the same level, which were regarded as incongruous or "atrophic".

Incongruous deformity of the spinal cord In nine patients the cord looked atrophic throughout most of the spinal canal. Seven had minimal or no compression at the craniovertebral junction and eight had moderate or severe compression usually at multiple subaxial cervical levels. Therefore atrophy is related to subaxial cord compression and not to compression at the craniovertebral junction, in this series $(p=$ $0 \cdot 008)$.

Congruous deformity of the spinal cord This was seen at the cranio-vertebral junction in 21 , at subaxial levels as well in five and alone in five. Sagittal measurements of the cord tended to overlap between the classification based on visual assessment as shown in fig 1, and it was felt that for clinical correlations cord deformity was best assessed visually. The anterior surface of the cord was the only surface deformed at the cranio-vertebral junction in $17(71 \%)$, and the cord was often shown not to be in contact with the deforming agent (mean separation $1.2 \mathrm{~mm}$, range 0 to $4 \mathrm{~mm}$ ). CT in flexion and extension (fig 5) showed an average percentage reduction in sagittal diameter of the theca of $31 \%$ (range $0-67 \%$ ) on flexion, and of the cord of $15 \%$ (range $0-50 \%$ ). The cord came into contact with the theca anteriorly when its sagittal diameter became narrowed, but in two cases there was up to $4 \mathrm{~mm}$ of subarachnoid space behind the cord. However, when the cord was deformed ono flexion it never reverted to normal on extension in this group of six patients. It is concluded therefore tha mechanical cord deformity becomes fixed, and cari occur without the necessity for a posterior com pressive element.

Normal cord shape Only two patients showed n\& cord abnormality at any level, and six showed none at the cranio-vertebral junction. In these the mean sepaco ration between the anterior surface of the cord and ${ }^{+}$ theca was $1.0 \mathrm{~mm}$, indicating that the close approximation of cord and theca does not necessarily produce congruous deformity of the cord.

\section{Skeletal and soft tissue abnormalities}

Severity of congruous cord deformity and measurement of atlanto-dental separation and sagittal canal diameter are compared in fig 6 . Trends are visible in this graphical representation but the actual figures as arranged do not reach statistical significance, presumably because the numbers are too small in each group.

Pannus was responsible for most of the distortion of the theca associated with congruous cord deformity in nine of the 21 relevant cases $(43 \%)$ (fig 7 ). Rarer types of craniovertebral subluxation were also seen: anterior atlanto-occipital, four cases; and two had severe cord deformity; vertical atlanto-axial, three cases, with only mild or moderate deformity of the cord in each (fig 8); and posterior atlanto-axial, two cases. 

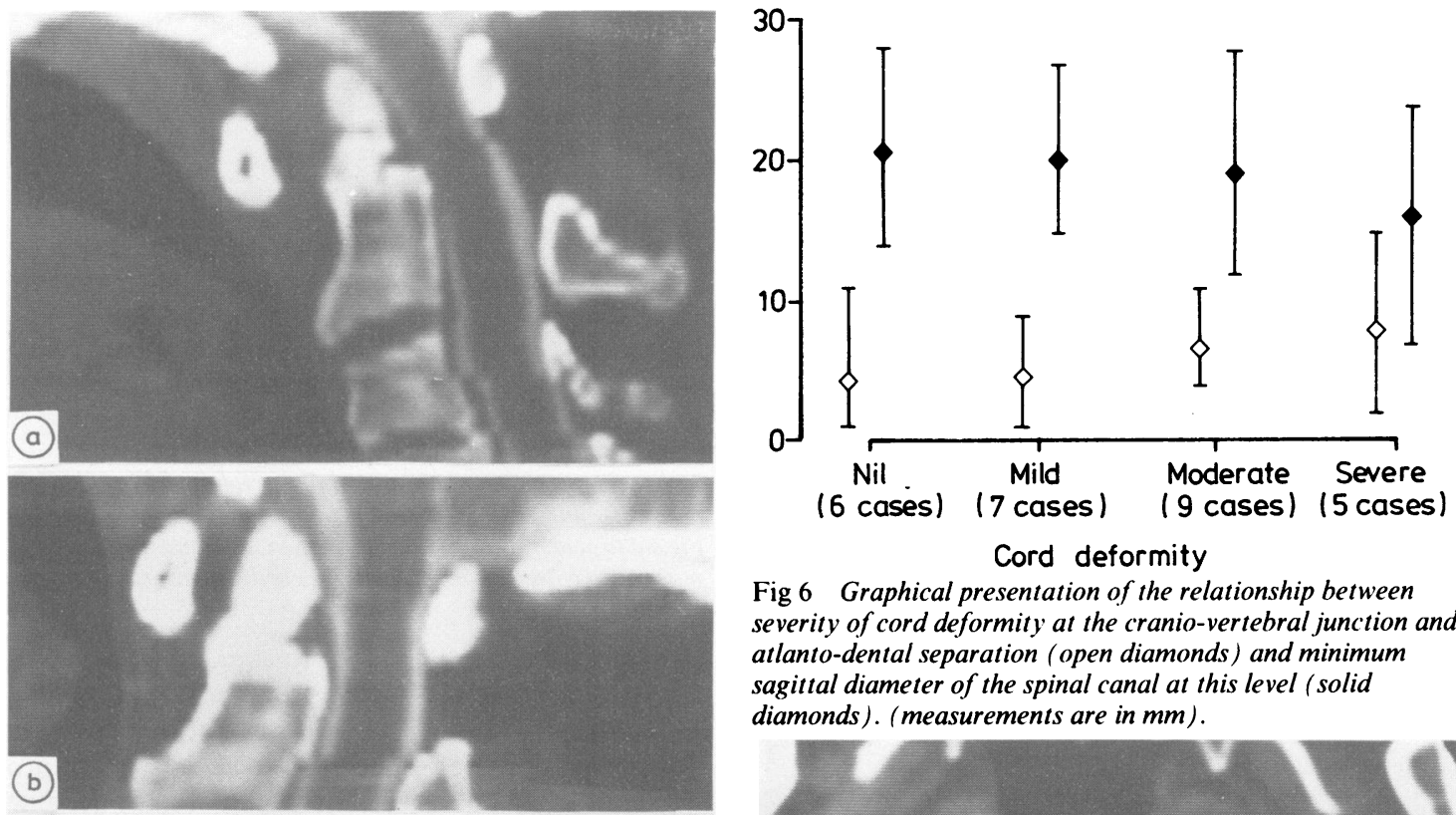

Fig 6 Graphical presentation of the relationship between severity of cord deformity at the cranio-vertebral junction and atlanto-dental separation (open diamonds) and minimum sagittal diameter of the spinal canal at this level (solid diamonds). (measurements are in $\mathrm{mm}$ ).
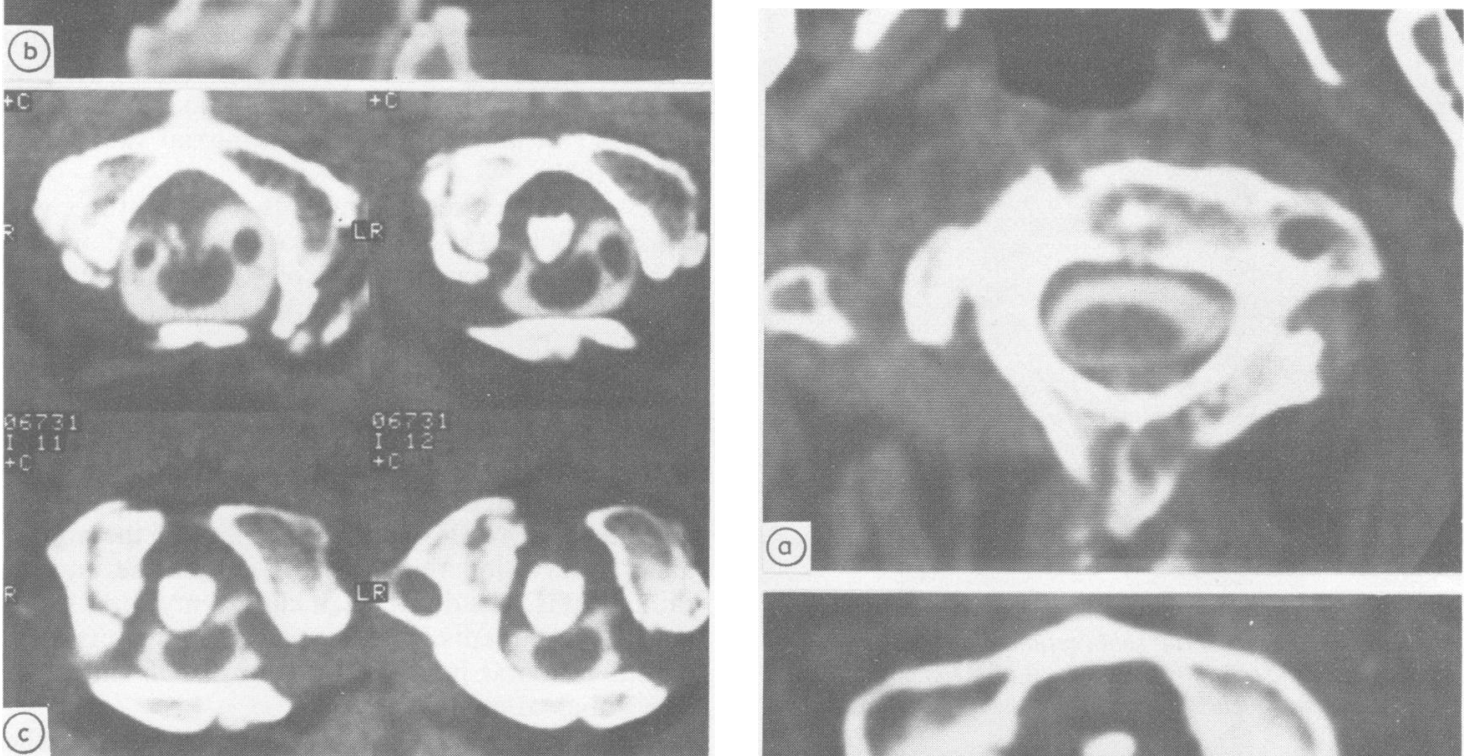

Fig 5(a) and (b) Flexion and extension CT, the sagittal reformats are not quite in the same sagittal plane. The cord is compressed in flexion, not in extension. (c) Axial images of the same examination in flexion showing severe congruous cord deformity.

The width of the subarachnoid space anterior and posterior to the cord is indicated in fig 9 . The posterior subarachnoid space was compressed from behind in seven cases, owing to anterior atlanto-occipital subluxation in two, pannus in two, and atlanto-axial rotation plus pannus in three. The cord was compressed against a normal posterior theca in a further

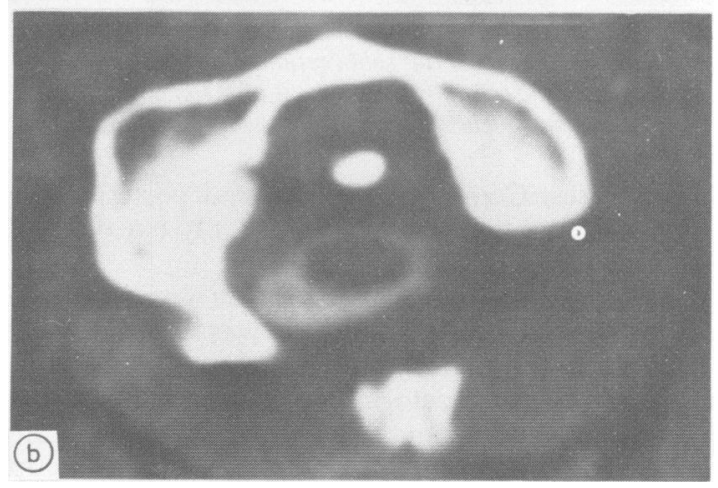

Fig 7(a) and (b) Axial CT images from a case in which pannus was the dominant agent determining the pattern of congrous cord deformity. Note the importance of posterior pannus also. 

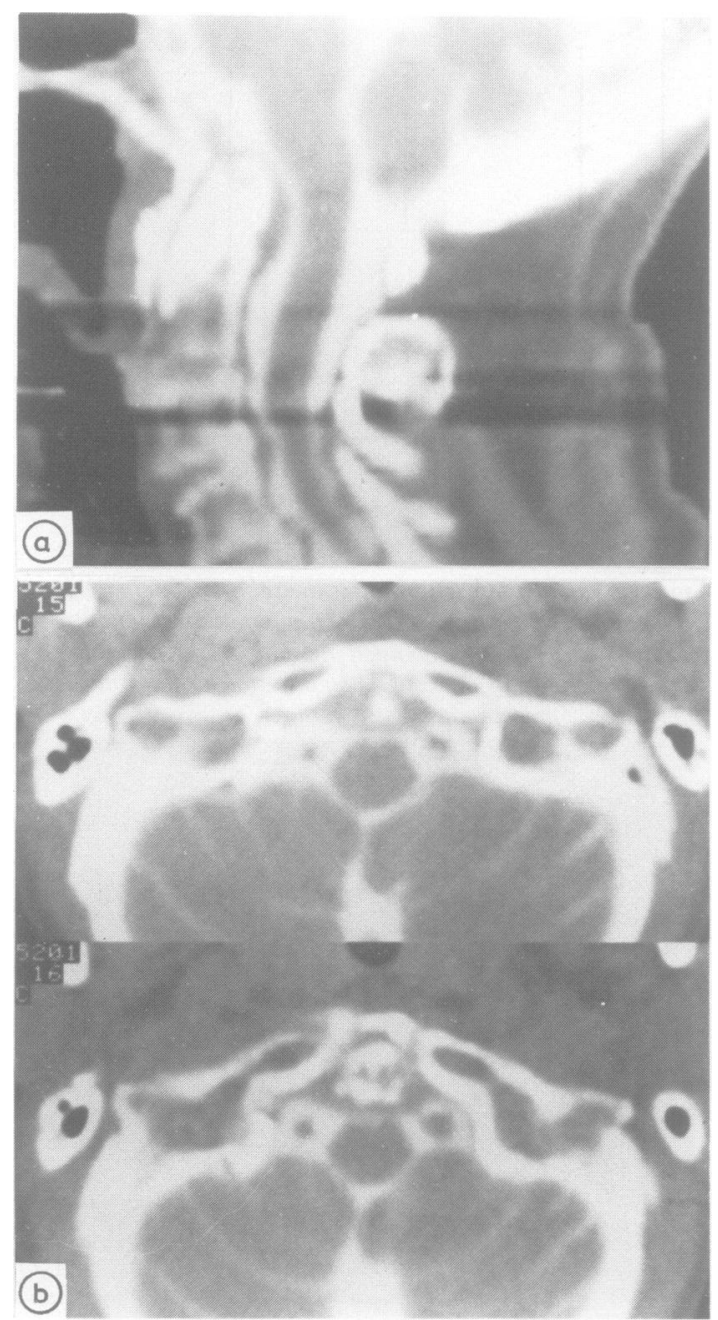

Fig 8 Sagittal reformat (a) and axial images (b) showing mild vertical atlanto-axial subluxation and mild congruous deformity of the infraolivary segment of the medulla. This patient had downbeat nystagmus and swallowing difficulties.

three cases. Combined anterior and posterior compression was therefore shown in only ten of the 21 relevant cases $(48 \%)$.

Lateral atlanto-axial subluxation was seen in 15 cases, and in nearly half (7) it was associated with lateralised cord deformity (fig 2).

Subaxial cord deformity occurred with a fixed angular kyphosis and vertebral collapse in three, single level anterior subluxation in four and multiple levels of subluxation ("staircase") in four.

Mobility of the atlanto-axial subluxation and severity of cord deformity are compared in fig 2 . A significant relationship between increasing mobility

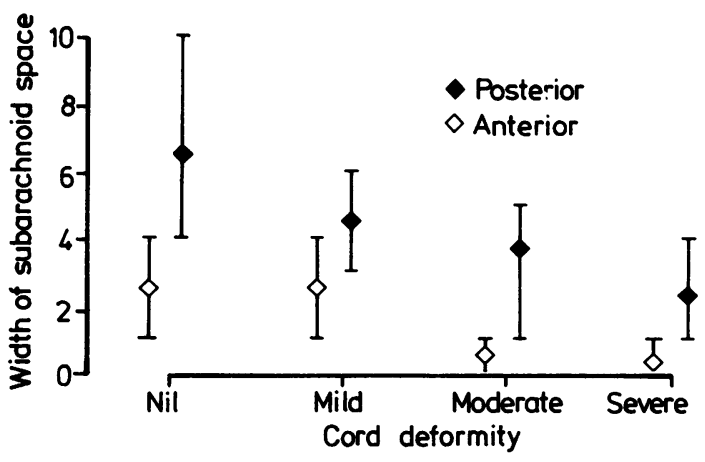

Fig 9 Graphical representation of the relationship between cord deformity at the cranio-vertebral junction and width of the subarachnoid space anterior (open diamonds) and posterior (closed diamonds) to the cord. (measurements are in $\mathrm{mm}$ ).

and greater cord deformity is shown: eleven of 14 cases with at least moderate cord deformity has more mobile subluxation, compared to three of 13 with mild or no cord deformity $(p=0.006)$. Flexion produced little or no movement at the atlanto-occipital joint in $26(84 \%)$, anterior atlanto-axial subluxation in $14(45 \%)$ and posterior atlanto-axial subluxation in two $(6 \%)$.

Several other skeletal and soft tissue features were considered: lengths of clivus, basal angle and anterior angulation of the neuraxis across the cranio-vertebral junction. No relationship with cord deformity was revealed.

\section{Clinical features}

The only clinical features which correlated with severity of cord deformity on CT were a combination of motor long tract signs and a sensory level, and they correlated more closely with mobility of the atlantoaxial subluxation than with its magnitude on plain radiographs. The duration of clinical myelopathy was shortest in patients with severe cord deformity at the cranio-vertebral junction, and longest in those with only subaxial involvement.

Motor long tract signs were counted present when there was spastic weakness worse in the legs, clonus, bilateral Babinski reflexes and gait disturbance. About half our patients (15) had these features, and about half of these (7) also had a sensory level somewhere between the sixth cervical and fifth thoracic segment. These signs, in combination, were taken as evidence of definite cord involvement.

Twelve patients complained of progressive weakness in the hands, legs or both but no signs could be elicited against a background of joint disease. Seventeen patients complained of paraesthesia usually in the arms, and six showed a positive Lhermitte's phenomenon. Bilateral glove-and-stocking anaesthesia 
Table 1 Clinical features compared to findings on computed myelography in 27 cases

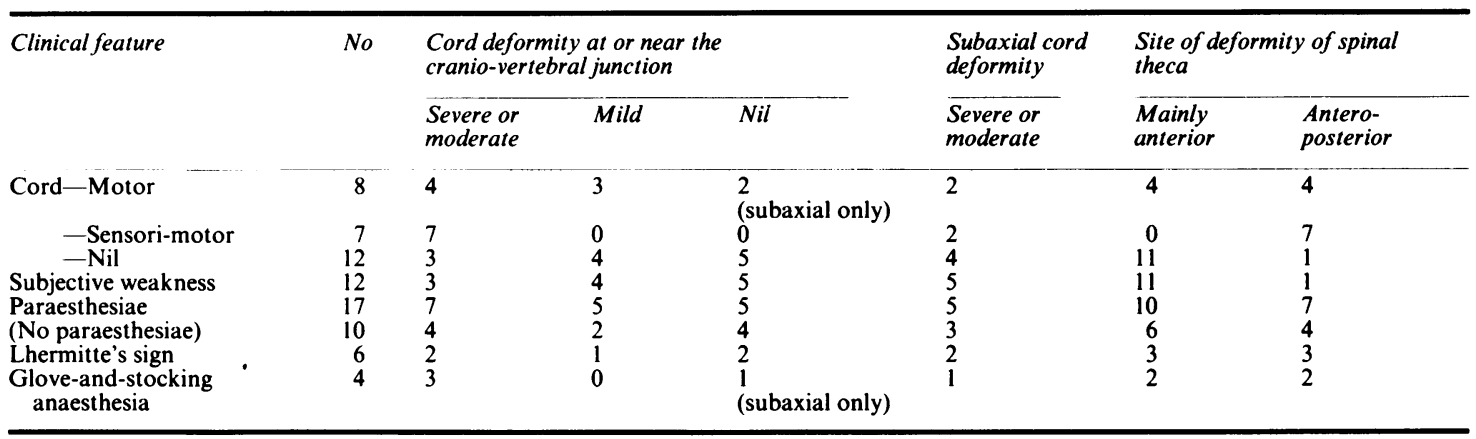

was found in four, hemianaesthesia in one, and patchy sensory loss in eight others.

Neck pain was a dominant feature in 19 patients, with occipital radiation in five. In eight, pain preceded the myelopathy by less than one year (five cases) or up to 17 years (three cases). Pain and myelopathy appeared together in seven, and myelopathy preceded pain by six to eleven months in three.

Features indicating hind-brain involvement were present in four patients, with swallowing difficulties in two and nystagmus in two (fig 8).

How these features were related to findings on computed myelography is shown in table 1. There was a significant correlation between definite cord involvement and severe or moderate cord deformity: seven of seven with involvement compared to three of 12 without $(p=0.002)$. A close relationship between these sensorimotor cord signs and combined anterior and posterior narrowing of the subarachnoid space was also revealed: seven of seven with signs compared to one of 12 without $(p=0.002)$. No patient with definite cord involvement had a normal cord on CT. The three patients with a normal cord on CT had subjective weakness, and one also had arm paraesthesia and a positive Lhermitte's phenomenon. Definite cord signs were lacking in three of the patients who had moderate or severe cord deformity $(25 \%)$, but were present in all such cases when cord compression was not just anterior alone. The presence of motor long tract signs, or any of the other clinical features considered in isolation, did not show a significant relationship with these CT findings.

Unilateral clinical features predominated in eleven cases. In over half (six) congruous deformity was concentrated on one side of the cord. Ipsilateral compression was seen with monobrachial paresis, paraesthesia and proprioceptive loss, and contralateral compression with hemiparesis, hemianalgaesia and in one, monobrachial paraesthesia (fig 2).

Further relationships with CT findings are shown in table 2. Short duration of clinical symptoms other than neck pain, was related to moderate or severe cord deformity at the cranio-vertebral junction (nine of eleven with short, compared to five of 16 with long or moderately long; $p=0.013$ ). Conversely long duration of symptoms correlated with the presence of subaxial sites of compression only ( 0 of 11 with short compared to eight of 16 with long, $p=0.012$ ).

Correlations with plain radiograph findings are shown in table 3 . There was a significant relationship between atlanto-dental separation of more than $10 \mathrm{~mm}$ and definite cord signs (five of 14 with less than $10 \mathrm{~mm}$, compared with six of eight with more than $10 \mathrm{~mm}, \mathrm{p}=0.048$ ). Unpredictability therefore occurred most frequently with atlanto-dental separations of between 5 and $10 \mathrm{~mm}$. Paradoxically neck

Table 2 Clinical features compared with findings on radiographs of the cervical spine in 31 cases

\begin{tabular}{|c|c|c|c|c|c|c|c|c|c|}
\hline \multicolumn{2}{|c|}{ Radiological feature } & \multirow[t]{2}{*}{ No } & \multirow[t]{2}{*}{ Cord signs } & \multirow[t]{2}{*}{ Paraesthesia } & \multirow[t]{2}{*}{ Pain } & \multirow[t]{2}{*}{$\begin{array}{l}\text { Lhermitte's } \\
\text { sign }\end{array}$} & \multicolumn{3}{|c|}{$\begin{array}{l}\text { Duration of clinical } \\
\text { features (months) }\end{array}$} \\
\hline & & & & & & & $1-6$ & $6-12$ & $12+$ \\
\hline $\begin{array}{l}\text { *Maximum } \\
\text { ADI (mm) } \\
\text { †Mobility } \\
\text { at Cl-2 }\end{array}$ & $\begin{array}{l}\leqslant 4 \\
5-9 \\
\geqslant 10 \\
\text { Marked } \\
\text { Mild-moderate } \\
\text { Fixed }\end{array}$ & $\begin{array}{r}14 \\
9 \\
8 \\
9 \\
5 \\
17\end{array}$ & $\begin{array}{l}5 \\
4 \\
6 \\
7 \\
4 \\
3 / 4\end{array}$ & $\begin{array}{l}9 \\
7 \\
1 \\
5 \\
5 \\
7\end{array}$ & $\begin{array}{r}12 \\
5 \\
2 \\
7 \\
4 \\
8\end{array}$ & $\begin{array}{l}2 \\
2 \\
2 \\
2 \\
2 \\
2\end{array}$ & $\begin{array}{l}3 \\
5 \\
5 \\
5 \\
3 \\
5\end{array}$ & $\begin{array}{l}5 \\
2 \\
2 \\
3 \\
2 \\
4\end{array}$ & $\begin{array}{l}6 \\
2 \\
1 \\
1 \\
0 \\
8\end{array}$ \\
\hline
\end{tabular}

*ADI is the atlanto-dental separation.

+"Mobility" refers to mobility at the atlanto-axial joint as defined in Figure 10. 
Table 3 Duration of clinical features compared to findings on computed myelography in 27 cases

\begin{tabular}{|c|c|c|c|c|c|c|}
\hline \multirow{2}{*}{$\begin{array}{l}\text { Duration of clinical } \\
\text { features }\end{array}$} & \multirow[t]{2}{*}{ No } & \multirow[t]{2}{*}{ Level } & \multicolumn{2}{|l|}{ Cord deformity } & \multicolumn{2}{|c|}{ Compression of the subarachnoid space } \\
\hline & & & Severe or moderate & Mild or nil & Anterior alone & Posterior \\
\hline Moderate (6-12 months) & 7 & $\mathrm{Cl}$ & 2 & 5 & 2 & 5 \\
\hline Short ( $<6$ months) & 11 & $\begin{array}{l}\mathrm{Cl} \\
\text { Subaxial }\end{array}$ & $\begin{array}{l}9 \\
0\end{array}$ & 2 & 3 & 8 \\
\hline
\end{tabular}

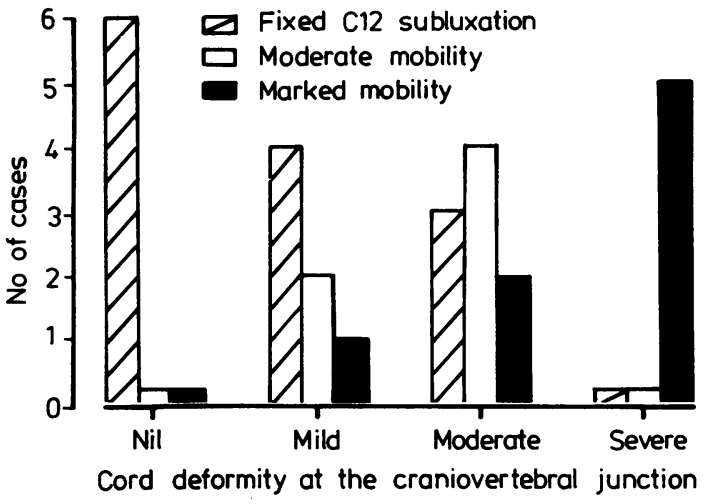

Fig 10 Bar graph to show the relationship between cord deformity at the cranio-vertebral junction and mobility of the atlanto-axial subluxation assessed from flexion and extension radiographs of the cervical spine. Fixed-movement less than $2 \mathrm{~mm}$; moderate, 2-9 $\mathrm{mm}$; marked, more than $10 \mathrm{~mm}$.

pain was more often a feature when atlanto-axial subluxation was relatively less ( 12 of 14 with less than $4 \mathrm{~mm}$, compared to seven of 17 with more than $5 \mathrm{~mm}$, $p=0.014)$. There were no correlations between these radiological features and pareasthesia, Lhermitte's phenomenon, duration of symptoms other than neck pain or sensory changes other than a sensory level.

Mobility of the atlanto-axial subluxation was significantly related to the presence of definite cord signs (11 of 14 with mild or marked mobility compared to four of 17 with no mobility, $p=0.003$ ). No correlations between mobility and other clinical features were found.

\section{Surgical results}

Only ten patients had no operation at the time of writing. Three refused, two were considered too poor a surgical risk for medical reasons, in one myelopathy was doubtful and myelography normal, and four are still being considered for operation. Of these, four were not followed up at our hospitals, one died, and those awaiting operations have not deteriorated as far as we know at this time.

Sixteen patients had a transoral odontoidectomy.
In 14 it was combined with posterior cranio-vertebral fusion, and in one with an anterior fusion; one operation had to be abandoned because the vertebral artery was encountered in front of the dens (fig 11). All patients successfully operated upon by this approach improved, in both neck pain and myelopathic features. Two required subaxial fusion as well. Two have deteriorated within two years but the rest have had sustained improvement for up to four years. There was not a significant relationship between improvement and any of the radiological variables considered above.

Post-operative radiographs of the cervical spine showed that seven of the posterior fusions in this group failed within two years. Moreover in nine odontoidectomy and interlaminar wiring caused vertical atlanto-axial subluxation of between 5 and $10 \mathrm{~mm}$. However, it was conspicuous that in all but two patients there was no recurrence of neck pain or any of the other clinical features despite this failure of immobilisation.

Four patients were treated by occipito-atlantoaxial interlaminar wiring alone. The dislocation was reduced in only two. One died of continuing cord compression within a year, one remained unchanged, one improved for about four months and then rapidly deteriorated, and one only showed a good sustained improvement.

\section{Discussion}

Distortion of the external form of the cord usually constitutes the only radiological evidence of myelopathy. Abnormalities within the substance of the cord can sometimes be shown by $\mathrm{CT},{ }^{2324}$ ultrasound $^{25}$ and magnetic resonance imaging $(\mathrm{MRI})^{26}$; but the conditions required for consistent results are too restricted for them to contribute in the present context, with the probable exception of MRI which has yet to be directed specifically at the problems addressed here. Although conventional myelography can show alterations in transverse and sagittal diameter of the cord, the cross-sectional images provided by $\mathrm{CT}$ give a more sensitive indication of distortion of external form than mea- 


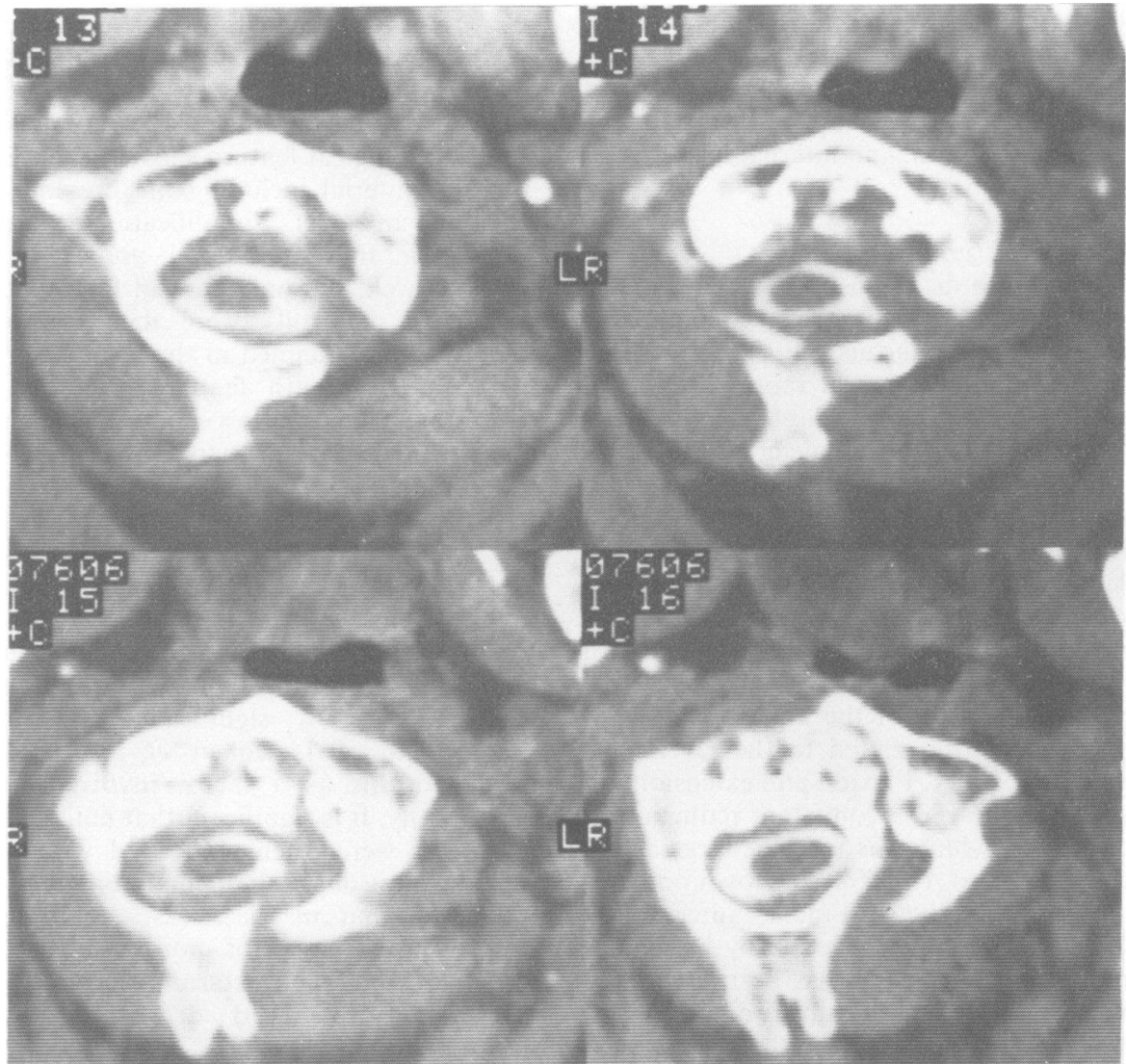

Fig 11 Axial CT images from a patient with atlanto-axial rotation and severe cord deformity largely due to pannus. In section 16 it is possible to deduce that the vertebral artery passing between the lateral masses of $C 1$ and $C 2$ has been rotated into the midline, and now lies in the transoral operative field just below the anterior tubercle of the arch of Cl. This arch is excised during operation; in this case the vertebral artery was injured and the operation had to be abandoned.

surements, for measurements contain unavoidable and considerable inaccuracies both on CT and conventional myelography. ${ }^{2728}$ Plain CT usually does not show the cord well enough to detect the small changes which our results have suggested may be relevant. Therefore, at the time of writing, intrathecally enhanced CT is the most sensitive radiological test for the detection of myelopathy.

To date, this aspect of the radiology of the spinal cord has received little attention. Some consideration, however, had been given to it in cervical spondylotic myelopathy, ${ }^{28}$ which has much in common with changes in the cord seen with rheumatoid arthritis, and recently in rheumatoid arthritis itself. ${ }^{29}$ Data from necropsy material has indicated only a very general and inconsistent relationship between the severity of external cord deformity, clinical features and histo- logical degeneration, and usually it is the surprising lack of close correlation between them that is emphasised. ${ }^{3031}$ In spondylotic myelopathy for example, severe cord deformity may be associated with no degeneration in cord substance, and in rheumatoid arthritis Hughes has stated that often little degeneration is seen in even markedly deformed cords, and this has been so despite the presence of clinical myelopathy. ${ }^{30}$ It has been suspected from necropsy material that cord deformity found in association with osteophytes was often nothing more than a postmortem fixation artefact, ${ }^{30}$ presumably because in these cases antero-posterior compression could not be inferred from the configuration of the spinal canal. Computed myelography has demonstrated emphatically, however, that these cord deformities exist during life: they are, as far as we can tell, fixed alterations 
in external form and are not dependent upon the continuous application of deforming forces.

Several distinct but closely related processes are operating to produce external cord deformity, neurophysiological dysfunction, and internal histological degeneration.

\section{Mechanism of cord deformity}

We have taken care to distinguish two types of cord deformity: congruous or compressive and noncongruous or atrophic. Congrous deformities were by far the most common. Graphical representation of the relationship to increasing atlanto-dental separation and decreasing sagittal diameter of the spinal canal shows the expected tendencies, but the figures in the sample were not large enough to be significant. The disparity between severity of cord deformity and these skeletal features usually could not be explained by pannus as some have suggested, ${ }^{8}$ and vertical atlanto-axial subluxation was not associated with severe cord deformity as it has been implied. ${ }^{9}$

In our material mobility of the atlanto-axial subluxation was significantly related to the severity of congruous cord deformity. Flexion and extension CT studies in six cases showed a consistent reduction in canal size on flexion which was twice as large as the changes seen in the cord. It has been shown on computed myelography that the cord moves anteriorly at the foramen magnum on head flexion by between 1 and $2.5 \mathrm{~mm}$, a movement which has been attributed to anterolateral traction from the upper digitations of the dentate ligament. ${ }^{21}$ The cord is therefore pulled against a potentially subluxing dens to a degree which varies somewhat from patient to patient. In this series anterior angulation of the neuraxis across the craniovertebral junction was not related in any way to anterior cord deformity. However, it may be that longitudinal tension in the cord is relevant, and this is known to be influenced by the posture of the entire spinal column,,$^{32}$ as is the relative position of the cord within the spinal canal. Combined anterior and posterior compression accounted for only about one third of cases in this material. Therefore it is suggested that the variable mechanical forces which tend to move and hold the cord anteriorly, and are brought to bear on head flexion, establish the conditions for deformation of the cord at the cranio-vertebral junction irrespective of the amount of free space present posteriorly.

\section{Mechanisms of clinical and histological myelopathy}

It is generally agreed that the presence and severity of myelopathy in rheumatoid arthritis is not predictable from plain radiographs. ${ }^{14516}$ The difficulties are intensified because it is not easy to interpret clinical signs in patients with severe joint disease. Laasonen $e t$ $a l^{29}$ recently claimed to have demonstrated a relationship between cord deformity on computed myelography and the severity of clinical features as graded by Ranawat et al. ${ }^{15}$ They emphasised that no other radiological feature showed such a correlation in their material including the presence of pannus. This is an over simplification which can be misleading. In our material, and quite possibly in theirs as well, the only clinical features to correlate with cord deformity were those of definite cord involvement as defined in the last section; there was no correlation with features such as neck pain, paraesthesia, Lhermitte's sign, subjective weakness or any sensory loss other than a sensory level, no matter how they were grouped. Furthermore, severe narrowing of the sagittal diameter of the spinal canal $(<15 \mathrm{~mm})$ and severe atlanto-dental separation $(>10 \mathrm{~mm})$ do correlate with clinical cord involvement, as has been stated by others. ${ }^{8915}$ Finally, pannus was a major factor in determining the pattern of cord deformity in nearly half our cases, and was certainly of significance in some of the illustrations of Laasonen et $a l^{29}$ although they dismissed this as a factor involved in producing myelopathy. It is significant that unilateral symptoms and signs were often associated with deformity of mainly one side of the spinal cord in our material, indicating that in these cases there was variable selective involvement of motor neurones, or crossed and uncrossed long tracts, and suggesting in turn that the pattern of cord deformity is of clinical importance.

The degeneration seen on histological preparations of the spinal cord in spondylotic myelopathy and rheumatoid arthritis has the appearance of ischaemic change or focal demyelination. ${ }^{\mathbf{3 0 3 1 3 3 3 4}}$ It probably often represents a stage of irretrievable cord damage and tends to be most marked at sites of greatest cord deformity, but may be entirely absent even in the presence of quite severe external changes. Rana et $^{\mathrm{al}} \mathrm{l}^{7}$ attributed the inconsistent relationship between skeletal changes and clinical features in rheumatoid patients to the variable response of the cord to trauma, and the concept of repetitive minor trauma has been propounded strongly in the case of spondylotic myelopathy also. ${ }^{35}$ Abnormalities in somato-sensory evoked responses in patients with intermittent medullary compression due to Chiari malformation have led Larson $e t \mathbf{a l}^{36}$ to suggest that some clinical features were evoked by disrupted synaptic transmission, mediated not by ischaemia, but by sheering strains within cord substance and intermittent geometric distortion of synaptic relationships. In our material, cord deformity was related to the presence of sensori-motor cord signs only when there was combined anterior and posterior 
compression of the subarachnoid space, and other clinical features occurred with variable degrees of cord deformity usually associated with anterior distortion of the theca only. Sensorimotor cord signs were also clearly related to mobility of the atlanto-axial subluxation, and less clearly to the magnitude of the atlanto-dental separation itself unless it was gross.

It is predictably very difficult to determine the relative importance of such mutually related variables as atlanto-dental separation, mobility, and available space for the cord. Moreover, even in well controlled animal experiments we know how variable can be the response of the cord to trauma ${ }^{37}$ and compression. ${ }^{38}$ Our data indicates that in rheumatoid myelopathy it is intermittently applied anterior deforming forces which are of paramount importance. Their effects depend upon their transmission to cord substance, which are maximised when space for the cord is restricted posteriorly whether by bone or pannus. In these circumstances traumatic disruption of cord substance, ischaemic damage due to reduced capillary perfusion, and overt functional failure are most likely to appear. Indeed, it can be speculated that the development of fixed congruous deformity of the cord is part of an adaptive phenomenon tending to protect cord substance from these effects, and the lack of correlation between clinical features, cord deformity or any other radiological variable then becomes more comprehensible. Diverse functional abnormalities possibly emerge from topographical alterations occurring within cord substance which are physiologically incompletely accommodated, and which need not be reflected in histological degeneration.

\section{Prognosis and results of operation}

Nakano ${ }^{4}$ has estimated that 30 or $40 \%$ of patients with rheumatoid arthritis develop cervical subluxation, and that only $2.5 \%$ will develop myelopathy. He has concluded that the myelopathy usually takes at least six years to develop and that within 14 years about $25 \%$ will deteriorate, $25 \%$ improve and $50 \%$ remain static.

In one prospective survey $40 \%$ of atlanto-axial subluxations did not progress in seven years. ${ }^{39}$ However, it has been estimated by others from different clinical materials that one-third of patients with vertical atlanto-axial subluxation die within ten years, ${ }^{9}$ and that as many as $50 \%$ or even $100 \%$ of patients with myelopathy will die within a year, although not necessarily of cord compression. ${ }^{26}$ In our material the patients with the shortest clinical course (less than six months) and most progressive clinical features were those who had mobile atlanto-axial subluxation combined with moderate or severe cord deformity at the cranio-vertebral junction.

Conservative treatment by collar or traction does not seem to significantly alter the clinical course, and traction may occasionally be harmful. ${ }^{671116}$ Operative treatment usually consists of posterior fusion following attempted reduction of the dislocation, sometimes combined with laminectomy; and a period of immobilisation in traction for six to 12 weeks following surgery has been the rule. ${ }^{71540}$ From the results in various publications, one can estimate an average operative mortality of $20 \%$ (range 10 to $70 \%$ ), and that only about $41 \%$ of operations (range 0-60\%) result in improvement. $^{256151639}$ The results of transoral odontoidectomy in this series provide a striking contrast: $86 \%$ produced sustained improvement and there were no perioperative deaths. One transoral operation had to be abandoned because rotation of the axis had carried the vertebral artery into the operative field anterior to the dens (fig 11). Symptoms of pain, subjective weakness and gait disturbances were most consistently relieved, sensory disturbances were less responsive. We feel that mobilisation on the third post-operative day was an important factor in achieving the low mortality in this series. Unfortunately, stable posterior fusion was achieved in only about half of these cases, although this is no worse than results reported for posterior fusion alone. It is highly significant that failed fusion resulted in recurrent symptoms in only about $14 \%$ of these cases compared with 80 to $90 \%$ where the dens had not been removed. ${ }^{2561516}$ Sound bony fusion is notoriously difficult to achieve in rheumatoid arthritis. However, these surgical results indicate that abnormal atlanto-axial movement is less significant once the compressing agents, in these cases the dens and pannus, have been removed.

Therefore a one-stage transoral extradural decompression and attempted posterior fusion with early mobilisation seems to present the best prospects of a satisfactory outcome for patients with atlanto-axial subluxation and myelopathy. Those patients with mobile atlanto-axial subluxation and congruous cord deformity are those most likely to progress to death within a few months if not offered operation. The demonstration of fixed deformity of the external form of the spinal cord at the cranio-vertebral junction we regard as an absolute indication for surgery, for this is firm evidence that atlanto-axial subluxation is affecting the cord. Computed myelography is the most sensitive test to detect this change. It is a safe and accurate test provided contrast is introduced via the lumbar route and not by lateral cervical puncture, where there is a danger of injuring the cord with the spinal needle or 
encountering a high cervical block and not obtaining information about the state of the lower cervical canal.

\section{Conclusion}

(1) Intermittent anterior pressure on the spinal cord is the cause of rheumatoid myelopathy, and this does not require combined anterior and posterior compression.

(2) The presence of clinical features is predictable only when there is combined anterior and posterior compression of the cord, and the only predictable features are combined sensorimotor long tract signs.

(3) Patients most in need of operation are those showing the most rapid clinical deterioration, and these are patients with mobile atlanto-axial subluxation in combination with cord deformity at the cranio-vertebral junction.

(4) Attempts at fusing the cervical spine often fail in rheumatoid patients, and immobilisation of the whole spine may be required to eliminate all possible consequences ensuing from anterior pressure on the cord.

(5) Excision of the actual compressing agents, that is dens and pannus, reduces or eliminates clinical manifestation of cord dysfunction even in the presence of mobile subluxation.

(6) Computed myelopathy using Iohexol introduced by lumbar puncture is the best way to investigate these patients at the present time.

The authors especially thank $\mathrm{Mr} \mathrm{S}$ Anathapavan for his tireless efforts in producing high quality CT images often under difficult circumstances. Gratitude is also extended to Beatrice Maher and Carolyne Williams for typing the manuscript and preparing some of the illustrations, and to Elizabeth Paul for advice on statistics.

\section{References}

${ }^{1}$ Redlund-Johnell I. Dislocations of the cervical spine in rheumatoid arthritis. Malmö, 1984 (Thesis).

${ }^{2}$ Meijers KAE, Cats A, Kremer HPH, Lugendijk W, Onvlee GL, Thomeer RJWM. Cervical myelopathy in rheumatoid arthritis. Clin Exp Rheum 1984;2:239-45.

${ }^{3}$ Eulderink F, Meijers KAE. Pathology of the cervical spine in rheumatoid arthritis: a controlled study of $\mathbf{4 4}$ spines. $J$ Pathol 1976;120:91-108.

${ }^{4}$ Nakano KK. Neurological complications of rheumatoid arthritis. Ortho Clin N Am 1975;6:861-79.

${ }^{5}$ Boyle AC. The rheumatoid neck. Ernest Fletcher Memorial Lecture. Proc R Soc Med 1971;64:1161-5.

${ }^{6}$ Marks JS, Sharp J. Rheumatoid cervical myelopathy. $Q J$ Med 1981;50:307-19.
${ }^{7}$ Rana NA, Hancock DO, Taylor AR, Hill AGS. Atlantoaxial subluxation in rheumatoid arthritis. $J$ Bone Joint Surg 1973;55(B):458-70.

${ }^{8}$ Stevens JC, Cartlige NEF, Saunders M, Appleby A, Hall $\mathrm{M}$, Shaw DA. Atlanto-axial subluxation $(\mathrm{Cl}-2)$ and cervical myelopathy in rheumatoid arthritis. $Q J$ Med 1971;40:391-408.

${ }^{9}$ Redlund-Johnell I, Pettersson H. Vertical dislocation of the $\mathrm{Cl}$ and $\mathrm{C} 2$ vertebrae in rheumatoid arthritis. In: Dislocations of the cervical spine in rheumatoid arthritis. Malmö, 1984:69-89 (Thesis).

${ }^{10}$ Maher JA. Dural nodules in rheumatoid arthritis: report of a case. Arch Pathol 1954;58:354-60.

${ }^{11}$ Hopkins JS. Lower cervical rheumatoid subluxation with tetraplegia. J Bone Joint Surg 1967;49(B):46-51.

${ }^{12}$ Crellin RQ, Maccabe JJ, Hamilton EBD. Severe subluxation of the cervical spine in rheumatoid arthritis. $J$ Bone Joint Surg 1970;52(B):244-51.

${ }^{13}$ Webb FW, Hickman JA, Brew DS. Death from vertebral artery thrombosis in rheumatoid arthritis. $\mathrm{Br} \mathrm{Med} \mathrm{J}$ 1968;2:537-8.

${ }^{14}$ Christophidis N, Huskisson EC. Misleading symptoms and signs of cervical subluxation in rheumatoid arthritis. Br Med J 1982;285:364-5.

${ }^{15}$ Ranawat CS, O'Leary P, Pellicci PM, Tsairis P, Marchisello P, Dorr L. Cervical spine fusion in rheumatoid arthritis. J Bone Joint Surg 1979;61(A):1003-10.

${ }^{16}$ Conaty JP, Mongan ES. Cervical fusion in rheumatoid arthritis. J Bone Joint Surg 1981;63(A):1218-27.

${ }^{17}$ Braunstein EM, Weissman BN, Seltzer SE, Sosman JL, Wang AM, Zamani A. Computed tomography and conventional radiographs of the craniovertebral region in rheumatoid arthritis. A comparison. Arthritis Rheum 1984;27:26-31.

${ }^{18}$ Halla JT, Fallahi S, Hardin JG. Nonreducible rotational head tilt and lateral mass collapse. A prospective study of frequency, radiographic findings and clinical features in patients with rheumatoid arthritis. Arthritis Rheum 1982;25:1316-24.

${ }^{19}$ Raskin RJ, Schnapf DJ, Wolf CR, Killian PJ, Lawless OJ. Computed tomography in evaluation of atlanto-axial subluxation in rheumatoid arthritis. $J$ Rheumatol 1983;10:33-41.

${ }^{20}$ Castor WR, Miller JDR, Russell AS, Chiu PL, Grace M, Hanson J. Computed tomography of the craniocervical junction in rheumatoid arthritis. $J$ Comput Assist Tomogr 1983;7:31-6.

${ }^{21}$ Osborne D, Triolo P, Dubois P, Drayer B, Heinz E. Assessment of the cranio-cervical junction and atlantoaxial relations using metrizamide-enhanced $C T$ in flexion and extension. AJNR 1983;4:843-5.

${ }^{22}$ Crockard HAC. The transoral approach to the base of the brain and upper cervical cord. Ann Roy Col Surg 1985 (in press).

${ }^{23}$ Pullicino P, Kendall BE. Computed tomography of "cystic" intramedullary lesions. Neuroradiology 1982; 23:117-21.

${ }^{24}$ Stevens JM, Olney JS, Kendall BE. Post-traumatic cystic and non-cystic myelopathy. Neuroradiology 1985;27:46-56.

${ }^{25}$ Montalvo BT, Quencer RM, Green BA, Eismont FJ, Brown MJ, Brost P. Intraoperative sonography in 
spinal trauma. Radiology 1984;153:125-34.

${ }^{26}$ Modic MT, Weinstein MA, Pavlicek, Starnes DL, Duchesneau PM, Boumphrey F, Hardy RJ. NMRI of the spine. Radiology 1983;148:757-62.

${ }^{27}$ Seibert CE, Barnes JE, Dreisbach JN, Swanson WB, Heck JR. Accurate CT measurement of the spinal cord using metrizamide: physical factors. $A J N R$ 1981;2:75-8.

${ }^{28}$ Yu YL, Stevens JM, Kendall BE, du Boulay GH. Cord shape and measurements in cervical spondylotic myelopathy and radiculopathy. AJNR 1983;4:839-42.

${ }^{29}$ Laasonen EM, Kankaanpaa U, Paukku P, Sandelin J, Servo A, Slatis P. Computed tomographic myelography (CTM) in atlanto-axial rheumatoid arthritis. Neuroradiology 1985;27:119-22.

${ }^{30}$ Trevor Hughes J. Pathology of the Spinal cord. 2nd Ed. London: Lloyd-Luke, 1978:169-75, 176-9.

${ }^{31}$ Ono K, Ota H, Tada K, Yamamoto T. Cervical myelopathy secondary to multiple spondylotic protrusions. A clinico-pathological study. Spine 1977;2:109-25.

${ }^{32}$ Breig A. Biomechanics of the Central Nervous System. Some Basic, Normal, and Pathological Phenomena. Upsala: Almquist and Wiksells, 1960.

${ }^{33}$ Wilkinson M. The morbid anatomy of cervical spon- dylosis and myelopathy. Brain 1960;83:589-617.

${ }^{34}$ Smith HP, Challa VR, Alexander E Jr. Odontoid compression of the brain stem in a patient with rheumatoid arthritis. J Neurosurg 1980;53:841-5.

${ }^{35}$ Adams CBT, Logue V. Studies in cervical spondylotic myelopathy I, II, and III. Brain 1971;94:557-94.

${ }^{36}$ Larson SJ, Sances A, Baker JB, Reigel DH. Herniated cerebellar tonsils and cough syncope. $J$ Neurosurg 1974;40:524-8.

${ }^{37}$ Guttmann L. Spinal Cord Injuries. Comprehensive Management and Research, 2nd Ed. London: Blackwell Scientific Publications, 1976:74-96.

${ }^{38}$ Gooding MR, Wilson CB, Hoff JT. Experimental cervical myelopathy. Effects of ischemia and compression on the canine cervical spinal cord. $J$ Neurosurg 1975;43:9-17.

${ }^{39}$ Winfield J, Cooke D, Brook AS, Corbett M. A prospective study of the radiological changes in the cervical spine in early rheumatoid disease. Ann Rheum Dis 1981;40:109-14.

${ }^{40}$ Ferlic DC, Clayton ML, Leidholt JD, Gamble WE. Surgical treatment of the symptomatic unstable cervical spine in rheumatoid arthritis . J Bone Joint Surg 1975;57(A):349-54. 